\title{
Correspondence
}

\section{Carcinoma of the lung in Lancashire coal miners}

Sir,-My friend Dr Rooke and his colleagues (April 1979 , p 229) have been kind enough to refer to a short paper of mine (Mooney, 1975a) in which 1 drew attention to the value of microscopy in the diagnosis of simple pneumoconiosis. As my belief in the importance of this has increased further during the past four years, I would value the opportunity of saying a little more about it, and about one or two other points in their interesting and important paper.

Recently, I completed a review of my findings on all necropsies of pneumoconiosis performed since 1957. These were all done on miners who, at the time of death, were either residing in, or within an approximate five mile radius of St Helens-a South Lancashire mining area. From 1957 until 1970 inclusive, the criteria I used for diagnosis were very similar to those used by Rooke et al-that is, naked eye examination and palpation. During that time 333 cases were classified as having pneumoconiosis and, of these, 32 $(9.3 \%)$ were found also to have lung cancer. This incidence compares closely with that reported by Rooke et al $(9.8 \%)$ during 1974-6. Towards the end of that period, however, statutory changes affecting coroners' necropsies led to microscopy being performed far more frequently than it had been in the past, and by 1972 it was being done in all necropsies of miners who had had chest symptoms during life. Two points quickly emerged. Firstly, the "miner's lung" was recognised easily, in most cases, from that of the non-miner. Secondly, it became increasingly apparent that a fair amount of simple pneumoconiosis had been previously escaping detection. Thus, not infrequently, half-a-dozen typical "stellate" nodules would be visible to the hand-lens on examination of the average-sized slide $(2.0 \times 1.5 \mathrm{~cm})$ where none had either previously been seen or felt. This is not surprising when it is realised that these tiny nodules are resting on a "cushion" of aerated lung tissue. Under these circumstances many of them are simply too small to be detected by simple finger and thumb palpation.

From 1971 to 1977 , therefore, microscopy has been used increasingly as an additional tool in diagnosis. During these years, out of 302 cases of pneumoconiosis, $52(17 \cdot 9 \%)$ also had primary lung cancer. During the same period, however, according to the registrar general, the average incidence of male deaths from lung cancer in St Helens was only $9.8 \%$. Furthermore, the trend is not upwards, as Rooke speculates, but downwards. Thus in 1971 the incidence was $11.2 \%$ whereas in 1977 it was only 8.2\%. Even allowing, in full, Heasman's (1962) generous assumption that 15$20 \%$ of lung cancers may escape detection, the difference remains clearly "significant" (that is, $>2.0 \times$ standard error). The smoking habits of miners and non-miners in a neighbouring South Lancashire town were found to be almost identical $(87.9 \%$ of miners were smokers as compared with $85.7 \%$ of non-miners). The quantity of tobacco consumed in each group was reported as "similar" (Higgins et al, 1956). Furthermore, Rooke et $a l$ in their series found that the smoking habits of miners developing carcinoma of the lung did not differ significantly from those without carcinoma. There does not appear, therefore, to be quite the difference between the smoking habits of miners as compared with non-miners, at least in this area, as Rooke and his colleagues would have us believe.

This extremely important problem, therefore, remains unresolved, and I have three suggestions to make. (1) Microscopy of the lungs should be performed on all miners who had chest symptoms before death, irrespective of naked eye appearances. This seems clear from the evidence already presented. Furthermore, miners who were classified by Rooke (table 1) as having "no pneumoconiosis" on naked eye examination, paradoxically, had a "significant excess" $(\mathrm{P}<0.05)$ of lung cancers! As all, apparently, had chest symptoms during life, one wonders how many of these might have been reclassified had microscopy been performed.

(2) It is high time that coal-dust ceased to be regarded as a homogeneous substance. I have already drawn attention to this (Mooney, 1975b). Coal dust always contains both silica and coal to a greater or less degree depending on the type of mine etc. Both these substances produce separate and distinctly identifiable lesions, which have been described more fully elsewhere (Mooney, 1975b). Although there is no reasonable doubt that the silica nodule is not associated with cancer, I am becoming increasingly aware of an apparent association between the small coal dust nodule of simple pneumoconiosis and malignant change in the lung (Mooney, 1975b). Coal itself does contain carcinogenic agents-especially certain derivatives of benzene. Over 40 years ago Shimkin (1939) found that $0.1 \mathrm{mg}$ of these-that is, methylcholanthrene and dibenzanthrene-were sufficient to produce multiple lung tumours when introduced into the trachea of mice. It would not be surprising, therefore, if thousands of tiny lung implants were found to be capable, over a period of years, of initiating lung cancer in some individuals.

(3) It seems an unnecessary complication that Rooke and his colleagues have chosen to compare "Lancashire coal miners" with the entire population of the "Northwest and Merseyside." Thus Liverpool, the largest city in that area, also happens to have one of the highest incidences of lung cancer in the entire British Isles. 
So far as I am aware, however, it does not contain a single coal mine! Inclusion of figures from areas such as these does little to clarify the problem. Since 1968 the registrar general has issued individual mortality statistics for individual towns in England and Wales. Thus it is now possible to compare not only one area with another, but also variations between individuals in the same community, according to occupations etc. I have used these statistics in presenting the above data. This seems altogether simpler, more accurate, and less confusing than the method chosen by Rooke. Certainly it will need more than Heasman's "correction factor," assumptions about "trends," or differences in smoking habits, to explain why, in this town, the chances of dying from cancer of the lung are almost doubled if a man also has pneumoconiosis.

Finally, 1978 offers little respite. During that year I performed 21 necropsies on cases of pneumoconiosis. Six of them also had cancer of the lung.

FRANCIS MOONEY Concultant pathologist, St Helens Hospital, St Helens, Lancs.

\section{References}

Heasman, M A (1962). Accuracy of death certification. Proceedings of the Royal Society of Medicine, 55, 733-740.

Higgins, I T T, Oldham, P P, Cochrane, A L, and Gilson, J C (1956). Respiratory symptoms and pulmonary disability in an industrial town. British Medical Journal, 2, 904.

Mooney, F S (1975a). Lancet, 1, 43.

Mooney, F S (1975b). Lancet, 1, 390.

Shimkin, M B (1939). Production of lung tumors in mice by intratracheal administration of carcinogenic hydrocarbons. American Journal of Cancer, 35, 538.

REPLY - We are grateful for the opportunity to reply to the points raised by Dr Mooney in his letter concerning our paper. Dr Mooney lays stress on the microscopic demonstration of pneumoconiotic foci in lung tissue and implies that more cases in our series should have been diagnosed as having some degree of pneumoconiosis. As pointed out in the discussion section of the paper, even if all our cases were assumed to have pneumoconiosis the overall prevalence of carcinoma in the whole group was $11.4 \%$, which is still no greater than in all male deaths in the area.

A higher proportion of miners' deaths are investigated at necropsy than in the general population because compensation is at stake. As Heasman (1962) showed, the relative infrequency of necropsies may lead to an underestimate of $20 \%$ of deaths due to lung cancer in the general population. For reasons given in the text of our paper we do not claim to have a complete sample of all miners who died in South Lancashire but Dr Mooney's sample is even less complete, and he makes no mention of the prevalence of carcinoma of the lung he found in coalminers without pneumoconiosis.

His mention of Liverpool as having one of the highest incidences of lung cancer in the British Isles, but having no coal mines, is surely a point in favour of our findings rather than of his. With regard to his criticism of the statistics we used for comparison we refer him to $p 233$ of our paper to show that we also made use of local as well as national sources.

With reference to smoking we showed that in those whose smoking history was known $91.8 \%$ had smoked and that of the 64 lung cancer cases where smoking history was known, $96.8 \%$ had smoked. Our series was relatively small, but considerably larger than $\mathrm{Dr}$ Mooney's for the years studied; a much larger study (Jacobsen, 1976) of more than 11000 British miners found that cigarette smokers had a nearly eight-fold excess of lung cancer deaths when compared with non-smoking miners.

G B ROOKE
F G WARD
A N DEMPSEY
J B DOWLER
C J WHITAKER
Pneumoconio $i$ Medical Panel,
Manchester.

\section{References}

Heasman, M A (1962). Accuracy of death certification. Proceedings of the Royal Society of Medicine, 55, 733-740.

Jacobsen, M (1976). Dust Exposure, Lung Disease and Coalminer's Mortality. PhD thesis, Edinburgh University. 